\title{
A creche e as famílias: o estabelecimento da confiança das mães na Instituição de Educação Infantil ${ }^{1}$
}

\section{The daycare center and the families: mothers' trust in the Institution of Early Childhood Education}

\author{
Isabel de Oliveira e Silva ${ }^{2}$
}

\begin{abstract}
RESUMO
Este artigo tem por objetivo analisar a questão do estabelecimento da confiança das mães de crianças de 0 a 3 anos na Instituição de Educação Infantil (IEI) pública. As análises dessa dimensão das relações entre família e Instituição de Educação Infantil foram realizadas tomando a noção de confiança desenvolvida por Anthony Giddens em sua análise das consequências da Modernidade. As análises apresentadas focalizam os sentidos e significados construídos pelas mães a respeito da opção pela creche como alternativa de apoio ao cuidado e educação dos filhos. Sustenta-se em pesquisa qualitativa, com realização de entrevistas individuais e em grupo com mães de crianças que frequentam instituições públicas de Educação Infantil. As conclusões indicam a agência das mães no processo de construção das relações com a IEI no que diz respeito ao estabelecimento de relações de confiança e da legitimidade da escolha por contar com a IEI pública para seus filhos desde bebês. Tal agência revela-se tanto no empreendimento de ações que reduzam a lacuna de conhecimentos dos familiares sobre a IEI bem como na busca por construir uma narrativa sobre a Educação Infantil e suas professoras que lhes ofereça maior segurança.
\end{abstract}

Palavras-chave: relação creche-família; compartilhamento; confiança.

DOI: $10.1590 / 0104-4060.36559$

1 Artigo originado da pesquisa Relação Escola-Família na Educação Infantil: a questão do compartilhamento do cuidado e educação das crianças pequenas. Apoio: Fundação de Amparo à Pesquisa de Minas Gerais (FAPEMIG) e Conselho Nacional de Desenvolvimento Científico e Tecnológico (CNPq).

2 Universidade Federal de Minas Gerais. Belo Horizonte, Minas Gerais, Brasil. Faculdade de Educação. Avenida Antônio Carlos, nº 6627. CEP: 31270-901. 


\begin{abstract}
This article aims to analyze the emergence of building trust by the mothers of children from 0 to 3 years old towards the public Institution of Early Childhood Education - Instituição de Educação Infantil (IEI). The analyses of this dimension of the relationships between the family and the Institutions of Early Childhood Education have been made based on the concept of trust as developed by Anthony Giddens as he analyzed the consequences of Modernity. The presented analyses focus on the senses and significances built by the mothers regarding their choice for the daycare center as the support for the children's care and education. They are founded on qualitative research involving both individual and group interviews with mothers whose kids attend public Institutions of Early Childhood Education. The conclusions indicate that the mothers act on the process of building a relationship with the school regarding the establishment of trust relationships and the legitimacy of the choice for the IEI for their children since the first years of their lives. This is shown by their actions towards reducing the lack of family knowledge about the IEIs as much as by the will to construct a narrative about Childhood Education and its teachers which will offer them more security.
\end{abstract}

Keywords: daycare center-family relationship; sharing; trust.

\title{
Introdução
}

Este artigo tem por objetivo analisar a questão do estabelecimento da confiança das mães de crianças de 0 a 3 anos na Instituição de Educação Infantil pública. A sociologia da educação contemporânea identifica a intensificação das interações família-escola, fenômeno que é tanto incentivado por políticas públicas de educação quanto demandado pelos pais de alunos dos ensinos Fundamental e Médio, conforme indicam pesquisas citadas por Nogueira (2006). A mesma autora afirma que não contamos, no Brasil, com estudos suficientes que deem conta das características de que se revestem essas novas formas de relações "no plano das trocas e interações face a face" (NOGUEIRA, 2006, p. 158). Fundamentando-se em literatura estrangeira, aborda as transformações nas famílias, tanto no plano de sua composição quanto no que se refere às relações de poder e às funções adquiridas pelos filhos nesse contexto. Assim, reconhecendo as profundas mudanças ocorridas na família com a instauração da modernidade, para cujo conhecimento os estudos de Phillipe Ariès foram pioneiros, recorre a outros autores que sustentam que tanto o caráter instrumental quanto o afetivo da relação entre pais e filhos sempre estiveram presentes e ainda permanecem 
nas novas configurações familiares. No entanto, a sentimentalização dessas relações, o caráter de investimento afetivo e de parâmetro para a aferição do sucesso e da autoestima dos pais intensificaram-se nas sociedades ocidentais contemporâneas.

A autora chama atenção para as transformações no sistema escolar, que vão desde a democratização do acesso e diversificação dos estabelecimentos de ensino, passando pela extensão da obrigatoriedade de matrícula e frequência, até as transformações nos planos curricular e dos métodos de ensino que, cada vez mais, implicam a família nos processos de escolarização dos filhos, configurando-se um alargamento da responsabilidade parental. Esse fenômeno, da visibilidade social da relação família-escola já seria, na visão de Pedro Silva (2003) suficiente para construirmos um olhar atento sobre ela e sobre seus efeitos para os envolvidos. O autor acrescenta, ainda, que "temos os argumentos que gravitam em torno do ponto de vista dos actores, aqueles que se encontram enredados em teias que, com maior ou menor habilidade, eles próprios tecem" (SILVA, 2003, p. 27).

No caso da Educação Infantil, pode-se dialogar com tais perspectivas analíticas tanto para apreender os sentidos que os filhos assumem nas famílias contemporâneas ao lado das grandes transformações que se vem operando nas últimas décadas (no Brasil) em que, cada vez mais, os cuidados iniciais e a educação dos bebês e crianças pequenas vêm sendo compartilhados com instituições educacionais: a Creche e a Pré-escola.

A tendência atual de favorecer a socialização das crianças em estruturas coletivas fora da família tem sido analisada de forma associada ao interesse generalizado por uma educação precoce. Destaca-se, ainda, que o ponto de vista de quem atua com crianças em determinados contextos é necessariamente parcial (a família e a escola). Mas, ao mesmo tempo, o ajuste dessas situações parciais modifica enormemente as condições ou o processo de socialização das crianças em nossas sociedades (MOLLO-BOUVIER, 2005).

Na realidade brasileira, o fato de já se ter conquistado, pelo menos no plano legal, o reconhecimento do direito à creche e à pré-escola vem favorecendo o desenvolvimento de orientações normativas e de uma produção de conhecimentos que podem contribuir para fundamentar e orientar as relações entre as famílias e as Instituições de Educação Infantil. A expansão do conhecimento sobre cada um dos ambientes de vida das crianças justifica-se, dentre outros elementos, pela importância de "apoiar a relação dos elementos de diferença para aumentar o ângulo de cada um dos pontos de vista em jogo" (FORTUNATI, 2009, p.48). O foco sobre os direitos das crianças como o eixo da organização do atendimento em creche não pode prescindir da consideração do ponto de vista das famílias, o que constituiria uma abstração: considerar as necessidades da 
criança de forma separada da sua realidade social e, portanto, das necessidades da família (BONDIOLI; MANTOVANI, 1998).

Embora ainda incipiente na área da Educação Infantil, não apenas relativamente à realidade brasileira (FRANCIS, 2000; MOSS, 2009), os estudos sobre as relações entre a Educação Infantil e as famílias das crianças atendidas têm procurado se aproximar dos sentidos e significados atribuídos pelos atores adultos ao compartilhamento do cuidado e da educação das crianças entre essas duas instituições (CASANOVA, 2011; MARANHÃO; SARTI, 2008; MARTINS, 2011; BAHIA; MAGALHÃES; PONTES, 2011; MORO; GOMIDE, 2003). E, cada vez mais, tais estudos analisam essas relações de forma articulada à sua importância para a qualidade do projeto pedagógico (ROCHA, 2001) e das experiências das crianças.

Com o objetivo de refletir sobre os processos por meio dos quais as famílias e, especialmente, as mães se relacionam com a creche, focalizamos, neste artigo, um dos elementos constitutivos dessa relação: o estabelecimento de confiança na instituição pública de Educação Infantil. As análises dessa dimensão das relações entre família e Instituição de Educação Infantil (IEI) foram realizadas tomando a noção de confiança desenvolvida por Anthony Giddens em sua análise das consequências da Modernidade e estudos empíricos sobre experiências de atendimento em creches no Brasil.

\section{A confiança: dimensão intrínseca à ideia de compartilhamento}

Qualquer que seja a origem social da família, a dimensão de confiança apresenta-se como um elemento central da relação IEI-criança-família. Para os responsáveis pelas crianças, trata-se de confiar seu filho ou filha a uma instituição, situação que a deixa desprovida da relação pessoal que, historicamente, marcou as relações de cuidado com os filhos (RAPOPORT; PICCININI, 2004). A conquista do direito traz consigo a impessoalidade e as regras universais que regem o serviço público, distanciando-se a prática de cuidado e educação em contexto coletivo da particularidade de cada família. Pode-se afirmar que a confiança na escola de Ensino Fundamental ou Médio passa antes pela imagem que ela é capaz de construir em termos de formação intelectual, adquirindo "importância crescente como instância de legitimação individual e de definição dos destinos ocupacionais" (NOGUEIRA, 2006, p. 161). Este aspecto, no caso da Educação Infantil, não deixa de estar presente, mas, especialmente na etapa creche (0 a 3 anos) é secundário em face das questões de segurança, saúde e bem-estar (MARANHÃO; SARTI, 2008; MARTINS, 2011). 
A questão da confiança pode/deve ser relacionada também à possibilidade de escolha, no caso, de com quem ou com que (no caso da instituição) compartilhar, às vezes por longas jornadas, o cuidado e a educação dos filhos. No caso da instituição pública, essa dimensão, a da escolha, está presente apenas parcialmente, especialmente para famílias que só podem contar com esse tipo de atendimento. Compete à família, pelo menos para as crianças até os 3 anos de idade, escolher se desejam (ou precisam) matricular seus filhos e filhas em IEIs. O que decorre dessa decisão foge ao seu controle, submetendo-se a regras únicas de atribuição de vagas (geralmente vinculadas ao endereço da família) e de profissionais que diretamente se responsabilizarão pelas crianças.

Analisando os elementos subjetivos da experiência social, em sua interpretação das consequências da Modernidade, Giddens (1991) afirma que se instaura nas sociedades ocidentais o que denominou de mecanismos de desencaixe. $\mathrm{Ou}$ seja, as transformações materiais e simbólicas pelas quais passaram e passam as sociedades ocidentais contemporâneas conformam formas peritas de provimento de diferentes necessidades humanas que dependem, fundamentalmente, da confiança. Esse autor vai definir o que denomina de "sistemas peritos" como "sistemas de excelência técnica ou competência profissional que organizam grandes áreas dos ambientes material e social em que vivemos hoje" (GIDDENS, 1991, p. 35). Tais sistemas removem as relações sociais das imediações do contexto (daí a ideia de desencaixe). Nessa direção, esses mecanismos pressupõem e, também, promovem "a separação entre tempo e espaço". E, nesse caso, sempre dependem da confiança em que funcionem, pois o leigo supostamente não conta com elementos para avaliar. O autor (1991, p. 83) complementa a noção de desencaixe com a de reencaixe como "reapropriação ou remodelação de relações sociais desencaixadas de forma a comprometê-las (embora parcial ou temporariamente) a condições locais de tempo e lugar".

Esse autor, recorrendo a Luhmann (1979) discorre ainda sobre a distinção entre crença e confiança, embora sejam sentimentos intimamente relacionados. Para ele, "a confiança deve ser compreendida especificamente em relação ao risco, um termo que passa a existir apenas no período moderno" (GIDDENS, 1991, p. 38). Isto quer dizer que a confiança depende da consideração dos riscos inerentes às ações e situações, o que não ocorre com a crença. Ainda com base em Luhmann, afirma que o caso normal é o da crença, uma vez que a vida exige que se negligencie a possibilidade de desapontamento, pois, do contrário, é viver na incerteza, privando-se da expectativa (crença) sem ter pelo que substituí-la. $\mathrm{Na}$ situação de confiança, o indivíduo considera conscientemente as alternativas para seguir um curso de ação, o que não ocorre no caso da crença, situação em que, diante do desapontamento, culpa-se o outro. No caso da confiança, assume-se 
parcialmente a responsabilidade (da escolha, da expectativa) podendo, inclusive, arrepender-se de ter depositado a confiança.

Giddens (1991) apresenta, ainda, outra definição para confiança. Para ele, confiança é um tipo específico de crença. A confiança relaciona-se à ausência no tempo e no espaço. Confia-se em alguém cujas ações não estão continuamente visíveis ou em sistemas que não se conhece ou compreende. Para ele, "a condição principal de requisitos para a confiança não é a falta de poder, mas a falta de informação plena" (GIDDENS, 1991, p. 40).

As análises que se seguem discutem os pontos de vista de mães de crianças que frequentam instituições de Educação Infantil sobre a escolha por essa alternativa de compartilhamento dos cuidados e da educação dos filhos e filhas. Trata-se de primeiros filhos ou de situação em que os filhos mais velhos não frequentaram creches. Assim, essa experiência se constitui na primeira situação em que essas mulheres se relacionam, como mães, com a Instituição de Educação Infantil. Essa condição se apresenta, do nosso ponto de vista, como uma situação de reduzido conhecimento sobre essa forma de cuidado e educação de bebês e crianças pequenas.

\section{Pontos de vista de mães de crianças entre 0 e 3 anos que frequentam creches}

A pesquisa que deu origem a este artigo foi iniciada em 2007 e continua sendo desenvolvida em outra IEI pública do município de Belo Horizonte. O objetivo geral é o de analisar as relações entre a Instituição de Educação Infantil pública e as famílias das crianças. Essa investigação tem procurado analisar diferentes aspectos das relações entre as famílias e as Instituições de Educação Infantil. $\mathrm{O}$ aspecto focalizado neste texto - a questão do estabelecimento da confiança na IEI por parte das mães das crianças - constitui-se, portanto, em um dos elementos problematizados na referida pesquisa. Analisam-se dados obtidos junto a mães de crianças de duas Unidades Municipais de Educação Infantil (UMEIs) que atendem a crianças de 0 a 6 anos no município de Belo Horizon$t^{3}$. Focaliza-se, portanto, o sujeito mãe de criança que frequenta a creche e os

3 As Unidades Municipais de Educação Infantil (UMEIs) foram criadas em 2003 por meio de Projeto de Lei encaminhado pela Prefeitura de Belo Horizonte à Câmara Municipal. Trata-se de Unidades vinculadas a Escolas de Ensino Fundamental, às quais se subordinam administrativamente, contando em sua gestão com uma vice-direção e coordenação pedagógica. Embora vinculadas a 
sentidos dessa escolha para ela. Essa parte da investigação adotou a abordagem qualitativa, apropriada para a obtenção dos sentidos e significados atribuídos pelos sujeitos às próprias experiências, às experiências de outros atores e a situações das quais participam (ALVES-MAZZOTTI; GEWANDSZNAJDER, 1999). A seleção das Unidades Municipais de Educação Infantil para o acesso a essas mães levou em conta características que permitissem abranger mães de diferentes estratos sociais.

Os dados foram obtidos por meio de entrevistas semiestruturadas. Nas duas instituições o acesso às mães foi mediado pela direção e ou coordenação. O local da entrevista com cada uma das mães foi sugerido por elas, o que se constituiu em um elemento facilitador de sua participação na pesquisa.

No caso da UMEI A, o contato com as mães e a solicitação de participação na pesquisa ocorreu em uma reunião de pais na instituição. Aquelas que se dispuseram a participar solicitaram que a entrevista fosse realizada na UMEI e manifestaram desconforto com o uso do gravador, razão pela qual os depoimentos foram registrados em caderno de campo. As mães cujos filhos frequentam a UMEI B foram abordadas nos horários de chegada ou saída das crianças da UMEI e, assim como no caso das mães da UMEI A, indicaram o local em que poderíamos realizar as entrevistas. Assim, as entrevistas com as mães de crianças da UMEI B foram realizadas nos seguintes ambientes: uma em seu ambiente de trabalho, outra em seu ambiente de estudo e outra em sua residência. Essas mães não se opuseram à utilização do gravador, tendo sido, portanto, as entrevistas registradas em áudio.

As duas instituições são públicas municipais e atendem a crianças de 0 até 6 anos. A UMEI A atendia a 270 crianças, sendo as de 0 a 3 anos em período integral (7:00h às 17:30h) e as de 4 até 6 anos em período parcial nos turnos da manhã (7:00h às 11:30h) e da tarde (13:00h às 17:30h). A UMEI B atendia a 440 crianças em período integral para todas as crianças de 0 a 3 anos e parte das crianças de 4 até 6 anos. As demais crianças de 4 até 6 anos eram atendidas em período parcial em turnos da mesma forma descrita acima para a UMEI A. Em ambas as instituições as professoras trabalham em jornada diária de 4 horas e trinta minutos havendo, portanto, para as crianças que permanecem na escola por jornada integral, o vínculo com diferentes professoras ao longo do dia. Para suprir toda a jornada das crianças de período integral, as duas UMEIs (como é o caso de toda a rede municipal para a Educação Infantil) adotam três turnos de professoras sendo um grupo no turno da manhã, outro em turno intermediário que cobre parte do turno da manhã e parte do turno da tarde e um terceiro

Escolas de Ensino Fundamental, essas Unidades funcionam em prédios próprios (PREFEITURA DE BELO HORIZONTE, 2003). 
grupo para o turno da tarde. Para as turmas de berçário e de crianças até 2 anos permanecem duas professoras com cada grupo de crianças, cujo número segue as normas do Conselho Municipal de Educação de Belo Horizonte.

No caso das mães, a característica comum a todas elas é a de que as crianças frequentavam a etapa creche ( 0 a 3 anos) e apenas o filho de uma delas a frequentava em jornada parcial, sendo então o horário integral o regime predominante.

A UMEI A localiza-se em um bairro de periferia do município, atendendo a uma população reconhecidamente pobre. Conforme depoimento da vice-diretora da UMEI A, a instituição foi construída num espaço de ação comunitária, começando a funcionar em março de 2005.

Nessa instituição, entrevistamos três mães de crianças: Nivalda ${ }^{4}$, que trabalha em regime de meio expediente, Andrea, cujo regime de trabalho não segue horários muito definidos ao longo da semana, com atividades nos finais de semana, e Taís, que estava desempregada e pretendia conseguir emprego em breve. Todas elas eram mães de crianças do berçário no momento da entrevista, com idades próximas de um ano e que passariam para a turma de crianças de 1 a 2 anos no ano seguinte (sala 1).

A Unidade Municipal de Educação Infantil - UMEI B é fruto da municipalização de uma instituição de Educação Infantil gerida por uma cooperativa de pais que funcionava no interior da universidade. Dentre os acordos do processo de municipalização houve a definição de $50 \%$ das vagas para filhos de professores, estudantes e funcionários da universidade. Embora essa instituição receba crianças de diferentes meios socioeconômicos e de diferentes bairros da cidade, neste artigo, optamos por trazer elementos obtidos com as mães dessa categoria (vinculadas à universidade) de modo a abrangermos um escopo mais alargado de condições sociais das famílias e das crianças. Não pretendemos qualquer representatividade em termos sociais, econômicos e culturais, mas consideramos relevante destacar tais condições na medida em que os sentidos atribuídos à experiência de compartilhar com a UMEI o cuidado e a educação das crianças certamente relacionam-se com o conjunto da experiência social dessas mulheres.

Na UMEI B, foram entrevistadas três mães de crianças: Paula, professora universitária, mãe de dois meninos gêmeos de um ano e sete meses que frequentavam a creche em horário integral; Áurea, estudante de doutorado, com uma filha de 3 anos e uma de um ano, ambas frequentando a UMEI; Marina, também professora universitária, com regime de trabalho parcial, mãe de um menino de 3 anos, grávida de 8 meses - seu filho frequentava a UMEI em período parcial.

4 Os nomes são fictícios, conforme Termo de Consentimento Livre e Esclarecido (TCLE). 
Todas as mães entrevistadas, das duas UMEIs, demonstraram empenho na relação com as instituições frequentadas por seus filhos e filhas e, também, disposição em falar sobre sua experiência para esta pesquisa. Nas entrevistas, especialmente com as mães cujos filhos ou filhas frequentavam tais unidades desde os primeiros meses e que não possuíam filhos mais velhos que tivessem tido essa experiência, pode-se constatar a centralidade da dimensão da confiança e de seu contraponto, a insegurança. As mães recorrem a recursos que, mesmo não correspondendo à realidade ou sustentados por diferentes argumentos, justificam, para si próprias, o acerto da decisão de compartilhar com essa instituição o cuidado e educação de seus filhos.

Uma das mães entrevistadas falou sobre a experiência de levar seu filho para a IEI, mencionando a avaliação que sua mãe (a avó da criança) fez das condições oferecidas pela instituição. Nesse caso específico, a avó teria mencionado o fato de serem duas professoras atuando concomitantemente com o grupo de crianças da faixa etária de seu filho. Segundo a mãe entrevistada, ela disse: estando duas, uma exerce vigilância sobre a outra. Observa-se que, mesmo tendo feito a opção pela creche, a avó continua exercendo um papel importante no cuidado com as crianças na família, nesse caso, como alguém que detém autoridade no assunto e que fornece um critério de avaliação da instituição para essa mãe. O mesmo foi identificado por Martins (2011), quando analisou expectativas de famílias com crianças menores de 4 anos, residentes em área rural, em que as avós cumprem um papel que ultrapassa a função de apoio, constituindo-se em fundamento das práticas familiares de cuidado e educação.

No caso dessa mãe, dando sequência à fala sobre o conselho de sua mãe, ela complementa:

E eu gostei muito da estrutura porque eles têm duas pessoas para cada turno com a sua criança, então, uma vigia a outra. Eu penso assim: a pessoa que está trabalhando não se cansa. Porque eu como mãe, eu nesses quatro meses e meio da minha primeira filha e mãe de primeira viagem, tinha momentos que eu me sentia muito cansada, sabe? [...] Eu ficava pensando: se é minha filha e eu estou cansada, sem paciência com ela, imagina o filho de outra pessoa? (Áurea, UMEI B).

Essa suposição de vigilância de uma professora pela outra foi manifestada também por outras mães entrevistadas. Trata-se de uma ação suposta pelas mães que, a rigor, por acontecer em um espaço a que elas não têm acesso na maior parte do tempo e por meio do exercício profissional de professoras que 
elas não conhecem, não pode ser comprovada por elas. No entanto, é certa a avaliação de riscos e a formulação dessa expectativa que lhes conferiram maior segurança, fazendo com que seus receios relativos a possíveis maus tratos a seus filhos fossem atenuados. Além disso, parece haver o reconhecimento de que a dimensão institucional do ambiente em que a criança é cuidada e educada oferece condições de controle das ações dos adultos com as crianças, tendo o papel de evitar situações causadas por circunstâncias pessoais como o cansaço ou a impaciência, como as relatadas por Áurea sobre sua experiência pessoal na vida familiar.

Ainda sobre a questão da escolha por matricular os filhos em uma UMEI, outras duas mães destacaram sua insegurança inicial, vencida pela observação da ação das professoras e, também, por uma avaliação de possíveis riscos de contratação de uma pessoa para estar com a criança no ambiente doméstico:

Andrea disse que considera muito arriscado deixar [o filho] em casa com pessoas desconhecidas, pois na TV sempre passam noticias de pessoas que agrediram crianças sob sua responsabilidade (Notas de campo sobre a conversa com Andrea, UMEI A).

E, sobre a resposta à pergunta de como tomou conhecimento sobre a UMEI, temos:

Andrea disse que foi por meio de uma pessoa conhecida que tinha filho em outra UMEI. Essa pessoa teria mencionado que se trata de uma instituição muito organizada, onde há disciplina. Esclareceu que seu desconhecimento a respeito é porque isso [creche pública] é novo em Belo Horizonte. (Notas de campo sobre a conversa com Andrea, UMEI A).

A ausência de experiência (ou de uma narrativa) própria por não terem frequentado uma creche quando eram crianças, bem como a ausência, com exceção de Andrea, no relato acima, de pessoas próximas que tenham vivenciado ou cujos filhos tenham tido essa experiência, parece ser um elemento que favorece a insegurança inicial. Além disso, a creche ainda é uma instituição que revela pouca capacidade de comunicação com o mundo exterior (BONDIOLI; MANTOVANI, 1998), havendo um contato permanente com as famílias que não se faz acompanhar de um processo intencional de comunicação por parte da 
creche de modo a proporcionar que os responsáveis tenham conhecimento sobre a experiência vivida pelas crianças no ambiente coletivo. Conforme destacado por Casanova (2011), observa-se a existência de circulação de informações, mas não de conhecimento que permita aos pais relacionarem o desenvolvimento das crianças às suas experiências nesse contexto.

No que concerne à legitimidade da escolha por compartilhar com uma instituição educacional o cuidado e a educação dos filhos, com exceção de uma das mães (Andrea) que deixou claro seu receio de ser considerada "como alguém que desejava ficar tranquila" por ter horário de trabalho flexível e mesmo assim candidatar-se a uma vaga para seu filho ainda bebê na UMEI, nenhuma das outras entrevistadas manifestou concepções que historicamente estiveram presentes nas justificativas para a oferta ou a demanda por creches: a ideia de um mal necessário (VIEIRA, 1986), diante da impossibilidade da única boa cuidadora (a mãe) de estar com a criança e, como é o caso de Andrea, a culpabilização das mães. O registro acima, com base na entrevista com Andrea, revela que para ela ter a referência por parte de alguém conhecido de que a instituição era bem organizada foi importante, destacando em seguida as razões do seu desconhecimento: a inexistência, no município, de instituições públicas de Educação Infantil, etapa creche, até muito recentemente 5 . Diferentes estudos revelam que o reconhecimento legal do direito das crianças não suprimiu representações que dificultam a legitimidade da creche como alternativa de cuidado e educação das crianças, constituindo-se referências ambíguas a esse respeito, o que reforça o sentimento de insegurança (MARANHÃO; SARTI, 2008). A ação deliberada da creche em fazer-se conhecer para o exterior é um elemento necessário para a transformação de sua imagem tanto para as famílias usuárias quanto para o conjunto da sociedade, este, tão importante quanto as primeiras (BONDIOLI; MANTOVANI, 1998).

As condições materiais de vida são, para todas as mães participantes da pesquisa, com maior centralidade para as mães da UMEI A, um fator considerado tanto para a inserção no mercado de trabalho quanto para a busca por uma instituição pública. As mães revelaram, também, que consideram os aspectos da formação e da profissionalidade na escola pública como um elemento que orientou sua decisão. Uma delas chegou a realizar uma comparação com determinada situação claramente distante de quaisquer padrões éticos aceitáveis, ocorrida em escolas de Educação Infantil particulares nas quais os vínculos

5 Em Belo Horizonte, a criação das UMEIs, a partir de 2004, constitui-se no início do atendimento público para as crianças de 0 a 3 anos, antes existente apenas na rede conveniada e na particular. 
profissionais eram muito frágeis. Ela assim se expressou, ao informar que tinha informações positivas sobre o funcionamento das UMEIs:

A preparação dos professores. [...] Por outro lado, eu tenho amigas que, por exemplo, faziam Pedagogia e, [...] na época que a gente era estudante, elas iam dar aula em escolinha, sem nenhum objetivo de ser professora da Educação Infantil, mas precisando de um dinheiro. Vai ali e faz um bico. Tem outros casos que eu já tinha ouvido falar [...], [que] quando chega pai na escola, elas [as professoras] começam a cantar uma música para todo mundo saber que tem pai na área (Paula, UMEI B).

E, na sequência, referindo-se à instituição pública, disse:

Enquanto que eu acredito que as pessoas que estão ali, concursadas numa UMEI, elas estão ali por opção. Então elas estão ali como carreira, não é? Não é aquela coisa assim, vou ganhar um dinheiro aqui, ali, que amanhã se der errado... [No caso da instituição pública], é uma carreira que a pessoa escolheu e quer fazer aquilo (Paula, UMEI B).

Também na conversa com Nivalda e Andrea, na UMEI A, encontramos a referência não diretamente à formação ou ao vínculo profissional, mas ao caráter público da instituição e de trabalho pedagógico, portanto, que exige conhecimentos específicos, como um fator que favorece a confiança:

Nivalda disse que tem três filhos e que nunca teve segurança de deixar os outros em creches, mencionando que as que existiam eram comunitárias. Para ela, na UMEI não é só tomar conta, as crianças têm uma formação. Andrea interveio e disse: "tem o pedagógico mesmo" (Notas de campo sobre conversa com Nivalda e Andrea, UMEI A).

As mães não conseguem, no entanto, precisar em que consiste esse trabalho que extrapola a dimensão do cuidado, revelando reduzida capacidade de comunicação da creche com as famílias a respeito do que se constrói em seu interior (BONDIOLI; MANTOVANI, 1998), o que também foi constatado por 
Casanova (2011) a respeito da apreensão de informações que não se traduzem em conhecimento sobre a experiência das crianças e suas repercussões no seu desenvolvimento.

Para todas as mães que foram entrevistadas ou que participaram de conversas sobre as razões pelas quais levaram seus filhos para a creche, a confiança aparece entre as primeiras menções, mesmo nos casos das mães de estratos socioeconômicos inferiores em que a questão da necessidade se impõe - necessidade de trabalhar e necessidade de contar com atendimento gratuito. Percebe-se que todas elas constroem alguma estratégia para justificar a escolha da creche como um lugar em que se pode confiar, seja pela expectativa de uma suposta vigilância dos adultos entre si, seja pela busca de informações a respeito da instituição pública.

O compartilhamento dos cuidados e da educação de bebês e crianças pequenas com instituições educativas vem sendo problematizado pela literatura da área, cujas análises são unânimes em indicar a importância de que a IEI favoreça a confiança da família na mesma (VITÓRIA, 1999; AMORIM; VITÓRIA; ROSSETTI-FERREIRA, 2000; MARANHÃO; SARTI, 2008; MARTINS, 2011; CASANOVA, 2011). Diferentemente de outras áreas da experiência social - como, por exemplo, a confiança que temos que depositar na perícia de um motorista que nos conduz, ou do médico que nos receita um medicamento - a educação e o cuidado das crianças são parte da experiência familiar cujos atores dominam o como fazer. O que nem todos dominarão é essa mesma ação em um ambiente coletivo, exercida segundo parâmetros distintos daqueles que orientam essa prática no ambiente privado. Assim, trata-se de uma tarefa fortemente enraizada nas relações parentais, com grande centralidade nas relações mãe-criança e que passa a ser realizada longe dos olhos dos familiares. As condições contemporâneas de provimento dos cuidados e da educação dos filhos é resultado de transformações materiais e simbólicas da nossa sociedade. Tais transformações levaram para o campo profissional (docência na Educação Infantil) ações que originalmente eram realizadas no ambiente doméstico. Está-se constituindo um sistema perito (GIDDENS, 1991), nesse caso, um sistema de competência profissional e de organização institucional que responde, em outro contexto, por relações que ocorriam exclusivamente no ambiente doméstico e sem a necessidade de perícia profissional específica, embora se verifiquem, entre as transformações contemporâneas das famílias, certa busca por "profissionalizar" por meio do acesso a conhecimentos específicos, a ação educadora que ali ocorre (cf. CHAMBOREDON; PRÉVOT, 1986; BONDIOLI; MANTOVANI, 1998).

E, nesse processo, a creche como um novo contexto de cuidado e educação é objeto da reflexão dos familiares. O distanciamento das ações de cuidado e 
educação dos bebês e crianças pequenas do ambiente doméstico, distanciamento tempo-espaço, exige confiança. Esta, por sua vez, está associada à noção de risco - de que as professoras se cansem ou que fiquem impacientes, do que podem decorrer ações inadequadas com as crianças. É essa consideração de risco que as leva a empreenderem ações para constituírem a confiança diante da escolha. Nessa direção, há uma implicação e um empenho dessas mães que buscam, de certa forma, reencaixar as relações que não estão sob seu domínio, ora avaliando condições que lhes indiquem controle do trabalho das professoras (uma vigia a outra), ora aproximando-se delas de modo a estabelecer relação afetiva (íntima, no dizer de uma das mães) com o objetivo de restabelecer elementos próprios das relações de cuidado no ambiente doméstico. Elas procuram reduzir a lacuna de conhecimentos sobre o que ocorre no interior da IEI, conforme relatos e excertos da pesquisa de campo acima mencionados.

Outro conjunto de relatos dessas mães indica, no entanto que, em alguns casos, mais do que confiança, elas mobilizam crenças que parecem ser capazes de neutralizar os receios de manterem, por longa jornada do dia, seus filhos sob os cuidados institucionais e profissionais longe de seu olhar. Embora a dimensão institucional seja acionada para destacar o seu caráter coletivo, o que se constitui em vantagem em comparação com a opção de contar com uma pessoa sozinha com a criança em casa, é a professora que cotidianamente estará em relação com as crianças a quem todas elas se referem.

No trecho a seguir, Nivalda, na sequência de seu comentário sobre sua necessidade de contar com uma instituição gratuita, acrescenta que:

No começo, veio insegura. Venceu a insegurança por observar o carinho das educadoras com as crianças. Disse que as educadoras ficam "na cola da gente" (Notas de campo sobre conversa com Nivalda, UMEI A).

A expressão "as educadoras ficam na cola da gente" foi explicada pela entrevistada ao longo de nossa conversa na qual ela esclareceu que há cobranças feitas pelas professoras acerca de atitudes, providências e ações das mães, em nome do bem-estar da criança. Essa ação das professoras, embora em outro contexto, segundo suas palavras, a incomodaria fortemente, nesse caso adquire para ela um significado de cuidado para com as crianças contribuindo para a elevação da confiança no trabalho delas.

Na mesma direção, diante da pergunta a uma mãe de criança da UMEI B sobre a razão pela qual ela possuía mais confiança na UMEI do que em uma pessoa contratada para cuidar dos filhos (gêmeos) em casa, ela mencionou: 
Quando eu fui na primeira reunião elas falaram que elas estavam lá porque elas queriam e gostam de estar lá. Elas trabalhavam com crianças porque elas queriam trabalhar com crianças. E isso me inspirou muita confiança, apesar de que eu já tinha total confiança antes, mas os meus contatos, meus contatos lá só reforçaram a minha confiança (Paula, UMEI B).

Na conversa realizada na UMEI A, temos um pequeno diálogo entre as mães, motivado por nossa pergunta sobre como viam as professoras das crianças, no qual elas destacaram a dimensão relacional e afetiva presente entre as professoras e as crianças e, também, entre elas e as mães. Esse elemento revela que essas mães, com crianças ainda muito pequenas que ainda não se expressam por meio da linguagem verbal, apresentam uma disponibilidade e um desejo de proximidade com as professoras como forma de fortalecimento de vínculos entre estas últimas e as crianças. Reproduzimos abaixo esse diálogo:

Andrea: [Elas são] professoras que ensinam, [mas] que são voltadas para elas [as crianças].

Taís: É, mas não pode esquecer o carinho que elas têm. Elas se tornam mães. Às vezes, se preocupam até mais que a mãe. Elas cuidam bem.

Nivalda: Elas são educadoras que têm muito carinho. Eu tenho um carinho muito grande por elas. Considero amigas. Não são como as professoras dos meus outros filhos [maiores]. Por elas, tenho afetividade.

Andrea: Criança pequena não fala, não pode contar.

Nivalda: Elas estão cuidando do bebê da gente. A relação é diferente.

Andrea: A cada dia a relação é mais próxima, mais íntima.

Nivalda: Elas sabem mais dos filhos da gente do que a gente.

(Notas de campo, registro das falas das mães da UMEI A)

As condições oferecidas pela IEI de abertura às famílias (AMORIM; VITÓRIA; ROSSETTI-FERREIRA, 2000) também operam na construção da confiança que as mães depositam. O diálogo acima expressa que a confiança inicial é um fator importante na escolha por levar o filho para a creche. $\mathrm{O}$ seu fortalecimento, no entanto, depende das relações estabelecidas entre a instituição, seus profissionais e as famílias (mães). Uma das mães refere-se à possibilidade de, em alguma medida, conhecer o que de fato se passa na UMEI, o que é 
viabilizado tanto pelas regras da instituição quanto por meio de uma "rede de mães" que conversam entre si e vai auxiliando nesse processo.

A creche me abria oportunidade pra vê-la [a filha] na hora da amamentação. Ou então na hora do almoço eu ficava lá e eu via o que estava acontecendo e tinha contato com outras mães. A gente conversava entre nós, via o que está acontecendo, entendeu? (Áurea, UMEI B)

Podemos observar a relevância de elementos afetivos na relação das mães com as professoras, em que são mobilizadas tanto informações mais ou menos objetivas quanto elementos da avaliação das mães sobre o que faz de uma pessoa capaz de cuidar e educar bem as crianças - ser mãe, fazer o que se gosta, estar ali por opção e não apenas como bico, estar atenta às crianças em grau mais elevado que as próprias mães. Tais afirmações revelam-se como crenças na medida em que são supostas pelas mães, revelando expectativas delas em relação às professoras, não se assentando em elementos objetivos. Como afirmou Giddens (1991), crença e confiança (que envolve elementos objetivos e certa avaliação de riscos), embora distintos, são sentimentos fortemente relacionados e ambos estão presentes nas relações mães-IEI-professoras. A mobilização desses sentimentos constitui-se em parte do empenhamento na construção do sentido de suas ações de compartilharem com a IEI o cuidado e a educação de seus filhos, ultrapassando o sentido da necessidade (ROSEMBERG, 2001) que, embora possa estar na origem da busca por esse serviço, não se constitui em justificativa suficiente.

Observa-se que nem a confiança, nem a sua ausência se assentam em elementos exclusivamente cognitivos - técnicas ou concepções. Ao contrário, as referências utilizadas por todas as mães baseiam-se tanto em informações quanto na ausência delas, na medida em que não podem dominar as regras e as contingências que regem o cotidiano da IEI e as ações das professoras. Nesse caso, mobilizam crenças e empreendem ações para reduzir a distância entre elas e a UMEI.

\section{Considerações finais}

As pesquisas que temos realizado com o objetivo de compreender os sentidos das ações das famílias, suas expectativas, angústias, dificuldades e, 
também, como a IEI interfere na vida familiar têm se revelado como uma forma de considerar os diferentes atores envolvidos na efetivação dos direitos das crianças. A questão do compartilhamento, a nosso ver, constitui-se mais como um desafio do que como uma prática dessa etapa da Educação Básica em nosso país. Desafio do ponto de vista conceitual, político e prático.

Uma das suas dimensões - a confiança que familiares de bebês e de crianças muito pequenas depositam ou não na IEI - revela-se como importante fator para a construção da qualidade das experiências proporcionadas aos meninos e meninas no ambiente institucional e também no ambiente familiar.

Os depoimentos de mães de crianças revelam a permanência de imagens de cuidadora e de educadora muito próximas daquelas que originalmente se associaram às educadoras nas creches, reproduzindo concepções que do ponto de vista legal não mais se sustentam, como é o caso da ideia de substituto materno. Longe, no entanto, de considerar que essas mães manifestam-se de forma ultrapassada, nosso esforço tem sido o de compreender o sentido que tais imagens assumem na experiência de compartilhar com a IEI os cuidados e a educação dos bebês. Cumpre traduzir para uma linguagem própria da oferta pública de Educação Infantil e das atribuições e aptidões profissionais das professoras e dos professores da Educação Infantil as habilidades e, fundamentalmente, o compromisso com as crianças, esperado tanto pelas mães individualmente, quanto pela sociedade quando define a creche e a pré-escola como direito das crianças e das famílias. Isto implica em constituir formas de efetivamente comunicar para o exterior as práticas e os conhecimentos construídos nessa instituição de cuidado e educação coletivos de crianças e de conhecer a experiência da criança e de seus pais em outros contextos.

Tomar a dimensão da confiança como um processo que envolve as duas instituições e os dois atores - familiares/pais das crianças e IEI/professores(as) - pode nos conduzir à instituição de práticas que a favoreçam, redirecionando as energias dos adultos envolvidos para maior compreensão das experiências das crianças que devem ocorrer em continuidade entre a IEI e as demais situações de sua vida (SANTOS, 2013).

Vimos que as mães (e avós), no caso dos sujeitos cujos relatos foram discutidos neste artigo, procuram agir sobre as condições contemporâneas de exercício da maternidade e, porque não dizer, da parentalidade (embora tenhamos conversado nesta pesquisa somente com as mães), empreendendo estratégias de redução das distâncias (reencaixe) e de construção de uma narrativa que lhes possibilite estabelecer a confiança na instituição e nas professoras.

Como educação compartilhada, as especificidades do ambiente coletivo serão sempre de maior domínio profissional, assim como compete à família a direção de suas ações na organização das experiências e das relações em seu in- 
terior. O sentido da experiência das crianças, no entanto, deve ser compartilhado de modo a que possamos tratá-la de forma integrada. Assim, torna-se possível oferecer aos atores adultos segurança para confiar no cuidado e na educação profissional de bebês e crianças pequenas na IEI e, nesse ambiente, segurança e tranquilidade para que professoras e professores construam relações fortes com as crianças e seus familiares.

\section{REFERÊNCIAS}

ALVES-MAZZOTTI, A. J.; GEWANDSZNAJDER, F. O método nas ciências naturais e sociais. São Paulo: Pioneira Thomson, 1999.

AMORIM, K. S.; VITÓRIA, T.; ROSSETTI-FERREIRA, M. C. Rede de significações: perspectiva para análise da inserção de bebês na creche. Cadernos de Pesquisa, n. 109, p. 115-144, mar. 2000.

BAHIA, C. C. S.; MAGALHÃES, C. M. C.; PONTES, F.A. R. A relação creche-família na visão de professoras e mães usuárias. Revista Ibero Americana de Estudos em Educação, v. 6, n. 2, 2011. Disponível em: <http://seer.fclar.unesp.br/iberoamericana/article/ view/4879/41 05>. Acesso em: 07/05/2014.

BERGER, P. L.; LUCKMANN, T. A construção social da realidade: tratado de sociologia do conhecimento. Petrópolis: Vozes, 1985.

BONDIOLI, A.; MANTOVANI, S. Manual de Educação Infantil: de 0 a 3 anos. Porto Alegre: Artmed, 1998.

CASANOVA, L. V. O que as crianças pequenas fazem na creche? As famílias respondem. Trabalho apresentado na 34 Reunião Anual da Anped. Natal, 2011.

CHAMBOREDON, J.-C.; PRÉVOT, J. O "ofício de criança": definição social da primeira infância e funções diferenciadas da escola maternal. Cadernos de Pesquisa, São Paulo, n. 59, p. 32-56, 1986.

FORTKAMP, E. H. T. Educação Infantil e família: a complementaridade na perspectiva das famílias de baixa renda. Dissertação (Mestrado) - Universidade Federal de Santa Catarina. Florianópolis, 2008.

FORTUNATI, A. A Educação Infantil como projeto da comunidade: crianças, educadores e pais nos novos serviços para a infância e a família - a experiência de San Miniato. Porto Alegre: Artmed, 2009. 
FRANCIS, V. Les mères des milieux populaires face a l'école maternelle: l'acces à l'information et rapport a l'institution. Les Sciences de l'Education, Caen (França), v. 33 , n. 4, p. 83-108, 2000.

GIDDENS, Anthony. As conseqüências da modernidade. São Paulo. Editora UNESP, 1991.

LUHMANN, N. Trust and Power. Chichester: Wiley, 1979.

MARANHÃO, D. G; SARTI, C. A. Creche e família: uma parceria necessária. Cadernos de Pesquisa, São Paulo, v. 38, n. 133, p. 171-194, jan./abr. 2008.

MARTINS, R. K. Expectativas das famílias do meio rural em relação à educação pública para os filhos menores de quatro anos. Trabalho apresentado na $34^{\mathrm{a}}$ Reunião Anual da Anped, Natal, 2011.

MORO, C. S.; GOMIDE, P. I. C. O conceito de infância na perspectiva de mães usuárias e não usuárias de creche. Paidéia, v. 13, n. 26, p. 171-180, 2003.

MOSS, P. Prefácio à edição inglesa. In: FORTUNATI. A. A Educação Infantil como projeto da comunidade: crianças, educadores e pais nos novos serviços para a infância e a família - a experiência de San Miniato. Porto Alegre: Artmed, 2009, p. 19-22.

MOLLO-BOUVIER, S. Transformação dos modos de socialização das crianças: uma abordagem sociológica. Educação e Sociedade, Campinas, v. 26, n. 91, p. 391-403, maio/ago. 2005.

NOGUEIRA, M. A. Família e escola na contemporaneidade: os meandros de uma relação. Educação e Realidade, p. 155-170, jul./dez. 2006.

PREFEITURA DE BELO HORIZONTE. Lei 8.679, de 11 de novembro de 2003. Cria Unidades de Educação Infantil no Município de Belo Horizonte e dá outras providências. Belo Horizonte, 2003. Disponível em: <www.jusbrasil.com.br/busca?q=Lei+8679\%2F $03 \% 2 \mathrm{C}+$ Belo+Horizonte> .

RAPOPORT, A.; PICCININI, C. A. A escolha do cuidado alternativo para o bebê e a criança pequena. Estudos de Psicologia, v. 9, n. 3, p. 497-503, 2004.

ROCHA, E. A. C. A pedagogia e a Educação Infantil. Revista Brasileira de Educação, n. 16, p. 27-34, jan./abr. 2001.

ROSEMBERG, F. Avaliação de programas, indicadores e projetos em Educação Infantil. Revista Brasileira de Educação, Anped/Autores Associados, n. 16, p. 19-26, jan./abr. 2001.

SANTOS, S. V. A gente vem brincar, colorir e até fazer atividade: a perspectiva das crianças sobre a experiência de freqüentar uma instituição de educação infantil. Dissertação (Mestrado) - Universidade Federal de Minas Gerais. Belo Horizonte, 2013. 
SILVA, P. Escola-família: uma relação armadilhada: interculturalidade e relações de poder. Porto/Portugal: Edições Afrontamento, 2003.

VIEIRA, L. M. F. Creches no Brasil: de mal necessário a lugar de compensar carências rumo à construção de um projeto educativo. Dissertação (Mestrado em Educação) Faculdade de Educação, Universidade Federal de Minas Gerais. Belo Horizonte, 1986.

VITÓRIA, T. As relações creche e família. Perspectiva, Florianópolis, v. 17, n. especial, p. 23-47, jul./dez. 1999.

Texto recebido em 25 de maio de 2014. Texto aprovado em 22 de julho de 2014. 